\title{
3
}

\section{Process Options for the Catalytic Conversion of Renewables into Bioproducts}

\author{
Pierre Gallezot
}

\section{1}

\section{Overview}

This chapter surveys different process options to convert terpenes, plant oils, carbohydrates and lignocellulosic materials into valuable chemicals and polymers. Three different strategies of conversion processes integrated in a biorefinery scheme are proposed: "from biomass to bioproducts via degraded molecules", "from platform molecules to bioproducts", and "from biomass to bioproducts via new synthesis routes". Selected examples representative of the three options are given. Attention is focused on conversions based on one-pot reactions involving one or several catalytic steps that could be used to replace conventional synthetic routes developed for hydrocarbons.

\section{2}

\section{Introduction}

The use of biomass for the production of energy, chemicals and materials is one of the key issues of sustainable development. Indeed, bio-based resources are renewable and $\mathrm{CO}_{2}$ neutral, in contrast with fossil fuels. Furthermore, owing to the rapid increase of oil price in 2005-2006 we face a new situation where the market price of crude oil ( $\left.€ 0.40-0.45 \mathrm{~kg}^{-1}\right)$ is higher than that of biomass-derived molecules such as sucrose or glucose. Also, the cost of molecules derived from carbohydrates or vegetable oils is fairly stable compared with that of fossil fuels and even tends to decrease steadily with time. Because of new ecological and economic incentives, government agencies or industrial organizations worldwide are actively promoting the use of renewables for energy and chemical production. Thus, the SusChem organization in Europe has published its Implementation Action Plan 2006 [1], advocating the use of renewables as alternative feedstocks that should be processed to bioproducts within an integrated biorefinery scheme. 
In addition to the incentives mentioned above, there is an additional interest to use renewables for the production of bioproducts. Thus, the molecules extracted from bio-based resources are already functionalized so that the synthesis of chemicals may require fewer steps than from alkanes, thereby decreasing the overall waste generated. Also, bio-based products may have unique properties compared with hydrocarbon-derived products, for instance biodegradability and biocompatibility. Biomass processing via clean catalytic routes involving a limited number of steps fulfils several principles of green chemistry at the same time [2]. Merely on economic grounds, products issued from biomass have a higher added value and their marketing is made easier because of their "natural" or "bio" label.

Diversified, cheaper sources of biomass rather than conventional crops are recommended for energy, chemicals and material production. Indeed, there is severe competition for the use of agricultural crops in the production of food/feed, bioproducts (chemical and polymers) and transportation biofuels (bioethanol and biodiesel). Conventional crops based on cereals and seed oils could only be a partial answer to the fuel issue because of the huge needs at stake [1]. To meet biofuel supply in a more substantial way, it is recommended to process agricultural wastes, new crops grown on marginal land, and vegetative biomass (wood, stems, leaves, etc.) consisting of fast-growing lignocellulosic plants rather than using cereals and oil seeds.

Various hurdles may hamper the development of renewables for bio-product production. The supply and composition of renewable raw materials vary with year and location of crops. This could be solved in the long term by using crops dedicated to chemical production and genetically engineered plants, giving a more constant supply and suitable composition that matches the desired products. The main issue is the high cost involved in processing renewable feedstock to chemicals. Processes employed for the synthesis of chemicals from fossil fuels improved continuously throughout over a century, resulting in a very high degree of technical and cost optimization. In contrast, processes to derive chemicals from biomass are comparatively in infancy and their cost weighs heavily on the market price of bioproducts. Accordingly, extensive R\&D efforts in biotechnology, chemistry and engineering are required to reduce processing cost. As outlined in Ref. [1] a prerequisite for expending the use of biomass-derived feedstocks is the development of alternative value chains. This can be achieved by designing processing routes and catalytic systems different from those employed from hydrocarbons and adapted to the specific molecular structure of biomolecules.

The present chapter focuses on process options integrated in a biorefinery scheme that should yield bio-products at a more competitive market price and quality. Although bioconversions are essential steps to derive the platform molecules that are used subsequently for catalytic transformations, only chemocatalytic process will be examined. Selected examples of catalytic conversions illustrating different process options will be given.

An important issue, not discussed in the present chapter, is the need to assess by life cycle analysis the sustainability of processes employing biomass instead of fossil fuels. Moreover, socio-economic life cycle assessment rather than simple 
conventional LCA should be performed to assess the societal impact of intensive agricultural activities covering much larger land area, leaving little space available for recreation areas, increasing the water stress and impairing the biodiversity.

\section{3}

\section{The Biorefinery Concept}

The biorefinery concept has been developed in food and paper industries and is now going to be applied for the production of energy, chemicals and materials from renewable feedstocks $[1,3,4]$. The underlying idea is to maximize the value derived from biomass by producing energy and multiple products via well integrated processes, valorizing co-products and by-products, and optimizing the inputs (energy, water, feedstock) and outputs (energy, products, treatments of gaseous emissions and waste water). In that respect biorefineries are quite comparable to petrochemical refineries. Part of the biomass is converted into fuels via gasification (syngas and hydrogen), pyrolysis (bio-oil), fermentation (biogas) while the other part is converted by successive operations involving hydrolysis, fermentation and chemo-catalytic routes into well-identified platform molecules that can be employed as building blocks in the synthesis of chemicals and polymeric materials. A simplified scheme of biorefinery operations designed for carbohydrate or lignocellulosic materials is given in Fig. 3.1.

The biorefinery scheme was developed initially for carbohydrate-containing feedstocks. Large biorefineries are currently operating in the USA (e.g., Cargill at Blair, Nebraska) and in Europe (e.g., Roquette Frs. at Lestrem, France). The concept can be extended to produce chemicals from other renewable feedstocks. An integrated production of oleochemicals and biofuels can be achieved in biorefineries using vegetables oils as main feedstock to produce versatile platform mole-

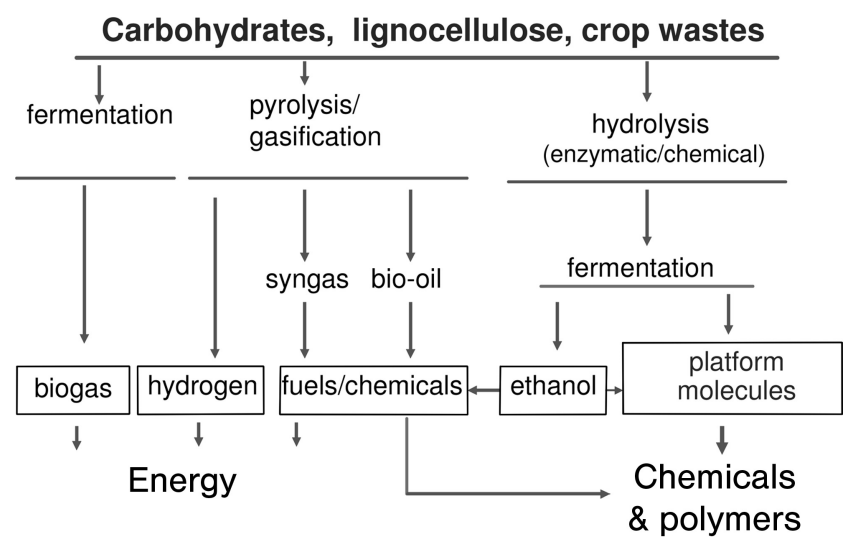

Fig. 3.1 Biorefinery scheme (simplified). 
cules such as fatty acids, fatty alcohols and glycerol. Similarly, the production of fine chemicals derived from terpenes can be integrated in a biorefinery scheme.

3.4

\section{Strategies for Biomass Conversion into Bioproducts}

Within the biorefinery framework several process options can be chosen to produce bioproducts from renewable feedstocks. We have identified the following three main options that will be illustrated by selected examples.

\subsection{1}

\section{From Biomass to Products via Degraded Molecules}

Biomass can potentially be converted into synthesis gas by adapting the well known gasification processes based on reforming conversions. Syngas is then converted via Fischer-Tropsch synthesis into methanol or hydrocarbons which are subsequently converted into chemicals via usual synthesis routes developed for petroleum feedstock. This approach has been little developed particularly for the production chemicals. The overall sustainability of these high temperature processes has to be established. An interesting alternative to conventional combined gasification/Fischer-Tropsch processes consists of performing aqueous phase reforming of biomass yielding directly alkanes. Thus, a water solution of ethylene glycol, glycerol and sugar-derived polyols was converted into hydrogen and alkanes at $550 \mathrm{~K}$ under $15-50$ bar pressure [5]. Different selectivities to $\mathrm{H}_{2}$, $\mathrm{CO}_{2}$ and alkanes were obtained, depending upon metal catalysts and support acidity. Silica-alumina supported, rhodium catalysts yielded over $50 \%$ alkanes. The reaction chain leading to liquid alkanes up to $\mathrm{C}_{15}$ involves the acid-catalyzed dehydration of sorbitol, yielding intermediates that are subjected to aldol condensation over solid base catalysts, and the resulting oxygenates are hydrogenated to alkanes over metal-supported catalysts [6,7]. Although the aim of these studies was to produce transportation fuels it would have been interesting to know more about the organic products formed during the dehydration step because they could be more valuable than the hydrocarbons. In future, biomass gasification or liquid phase reforming employed for fuel production should be conducted using organic wastes or cheap and abundant vegetative biomass rather than high priced molecules such as sugar polyols obtained from cereals.

Another approach to produce chemicals via degraded molecules is the fast pyrolysis of biomass at high temperatures in the absence of oxygen. This gives gas, tar and up to 80 wt.\% of a so-called bio-oil liquid phase, which is a mixture of hundreds molecules. Some of compounds produced by pyrolysis have been identified as fragments of the basic components of biomass, viz. lignin, cellulose and hemicellulose. The bio-oil composition depends upon the nature of starting 
materials and process conditions [8, 9]. Beside bio-oil application in energy production some valuable compounds present in bio-oils, particularly phenolic compounds issued from the degradation of lignin, can potentially be recovered,. Furfural and furfuryl alcohol are present at up to 30 and $12-30 \%$, respectively. Phenol-formaldehyde resins have been prepared from bio-oils containing a high fraction of phenolic compounds [10, 11]. Although bio-oils are presently of interest for heat and power generation, their use as a source of chemicals may become attractive in future. The present situation is very much like the early days of coal and petrochemical industry, i.e., a great deal of research and process development is still needed.

At any rate, gasification or pyrolysis of biomass are energy demanding processes so that the production of energy or chemicals via these routes should be submitted to life cycle analysis to assess their sustainability. For chemists involved in the synthesis of bio-products employed as specialties and fine chemicals, this approach is not attractive because the highly functionalized molecules obtained from renewables are first deeply degraded, even down to $\mathrm{C}_{1}$ and $\mathrm{H}_{2}$ species in the case of gasification, before being subjected to conventional chemical synthesis routes in order to be functionalized again into valuable chemicals.

\section{4 .2}

\section{From Biomass to Products via Platform Molecules}

\subsubsection{Identification of Main Platform Molecules}

As far as carbohydrates are concerned, several platform molecules are already well identified and currently employed to produce specialties and fine chemicals. Monosaccharides such as glucose, and disaccharides such as sucrose, which are easily obtained with great purity from various carbohydrate-containing crops are well-known platform molecules in sugar chemistry. Lactose, with a production of $6 \times 10^{5} \mathrm{t} \mathrm{a}^{-1}$, is also a useful platform molecule obtained from the cheese industry. Most other platform molecules are obtained via fermentation from glucose or other carbohydrates using continuously improved processes with new genetically modified bacteria or yeasts [12]. The followings biomass-derived platform molecules are potentially useful building blocks for chemical synthesis: aspartic acid, 1,4-diacids (succinic, fumaric and malic), ethanol, glutamic acid, glucaric acid, 2,5-hydroxymethylfurfural, 2,5-furan dicarboxylic acid, 3-hydroxypropionic acid, 2hydroxypropionic acid, itaconic acid, levulinic acid, 1,3-propanediol. The list includes the top 12 platform molecules identified by the US department of Energy [13]. In future, the challenge will be to produce fermentable sugars from cellulose and hemicelluloses, which are available in huge amounts from vegetative biomass. This involves progress in the chemical and enzymatic hydrolysis of cellulose [12].

Vegetable oils or triglycerides obtained from the seeds of various plants are the source of a wide variety of fatty acid esters and derivatives (fatty acids and alcohols) with different molecular structure (chain length, number and position of 
$\mathrm{C}=\mathrm{C}$ bonds) that can be used as platform molecules, as well as glycerol, which is a co-product of triglycerides transesterification.

The three main platform molecules employed in terpene chemistry are $\alpha$ pinene and $\beta$-pinene, which are extracted from turpentine oil $\left(350000 \mathrm{t} \mathrm{a}^{-1}\right) \mathrm{a}$ co-product of paper pulp industry, and limonene extracted from citrus oil (30000 $\left.\mathrm{t} \mathrm{a}^{-1}\right)$.

\subsubsection{Selected Examples of Platform Molecule Conversion into Bioproducts}

Terpenes Terpenes [ $\alpha$-pinene (1), $\beta$-pinene (2), and limonene (3)] are employed in the synthesis of flavors and fragrances $(F \& F)$, although these compounds are often obtained by catalytic routes from hydrocarbons.<smiles>CC1=CC2CC3CC1C2(C)C3</smiles>

1<smiles>C=C1CC2CCC1C2(C)C</smiles>

2<smiles>C=C(C)C1CC=C(C)CC1</smiles>

3<smiles>Cc1ccc(C(C)C)cc1</smiles>

4

$p$-Cymene (4), a precursor of $p$-cresol and various F\&Fs, was obtained by dehydrogenation of $\alpha$-pinene at $300{ }^{\circ} \mathrm{C}$ in a continuous fixed-bed flow reactor in the presence of 0.5 -wt.\% $\mathrm{Pd} / \mathrm{SiO}_{2}$ [14]. Under similar conditions, but starting from limonene, $p$-cymene was obtained in $97 \%$ yield and the catalytic activity was stable for $500 \mathrm{~h}$ on stream [15].

The liquid phase alkoxylation of limonene (3) with $\mathrm{C}_{1}-\mathrm{C}_{4}$ alcohols to 1-methyl4 -[ $\alpha$-alkoxy-isopropyl]-1-cyclohexene (5) was carried out both in batch and continuous fixed-bed reactor at $60{ }^{\circ} \mathrm{C}$ on various acidic catalysts (Scheme 3.1) [16]. The best yields were obtained in batch $(85 \%)$ or continuous reactor $(81 \%)$ using a $\beta$-type zeolite with $\mathrm{SiO}_{2} / \mathrm{Al}_{2} \mathrm{O}_{3}=25$.<smiles>C=C(C)C1CC=C(C)CC1</smiles>

3<smiles>CC1=CCC(C(C)(C)O)CC1</smiles>

5

Scheme 3.1 


\section{Carbohydrates}

Glucose and Fructose Sucrose (total production $130 \times 10^{6} \mathrm{t} \mathrm{a}^{-1}$ ) and starch $\left(40 \times 10^{6} \mathrm{t} \mathrm{a}^{-1}\right.$ used in industry) are two major sources of glucose and fructose. A much larger supply of glucose or other fermentable sugars is expected to be obtained at lower cost in the future by advanced enzymatic processing of cellulose [12]. It is not the purpose of the present chapter to review the numerous catalytic reactions starting from glucose to derive valuable chemicals. Reviews have been given by van Bekkum and Besemer [17] and by Lichtenthaler and Peters [18]. The trend is to develop heterogeneous processes where the catalysts are recycled many times or used in continuous reactor for a long time on stream. Hydrogenation of glucose to sorbitol [19] and oxidation of glucose to gluconic acid [20] are illustrative examples of very selective catalytic conversion (yield $>99 \%$ ) where the catalysts are used many times with negligible loss of activity and selectivity.

There is great interest in converting glucose available in large supply into $\mathrm{C}_{5}$ and $\mathrm{C}_{4}$ polyols that are little present in biomass and find many applications in food and non-food products. Thus, glucose can be converted into arabitol by an oxidative decarboxylation of glucose to arabinonic acid followed by hydrogenation to arabitol (Scheme 3.2). The main pitfall is to avoid dehydroxylation reactions leading to deoxy-products not compatible with the purity specifications required for arabitol. Aqueous solutions (20 wt.\%) of arabinonic acid have been hydrogenated on Ru-catalysts in batch reactor [21].

The selectivity was enhanced by adding small amounts of anthraquinone-2sulfonate (A2S), which decreased the formation of deoxy by-products. Thus, by adding $260 \mathrm{ppm}$ of A2S with respect to arabinonic acid the selectivity to deoxyproducts decreased from 4.2 to $1.6 \%$. A2S acted as a permanent surface modifier since the catalyst was recycled with the same selectivity without further addition of A2S. The highest selectivity to arabitol was $98.9 \%$ at $98 \%$ conversion, with a reaction rate of $73 \mathrm{mmol} \mathrm{h}^{-1} \mathrm{~g}_{\mathrm{Ru}}{ }^{-1}$ at $80{ }^{\circ} \mathrm{C}$.

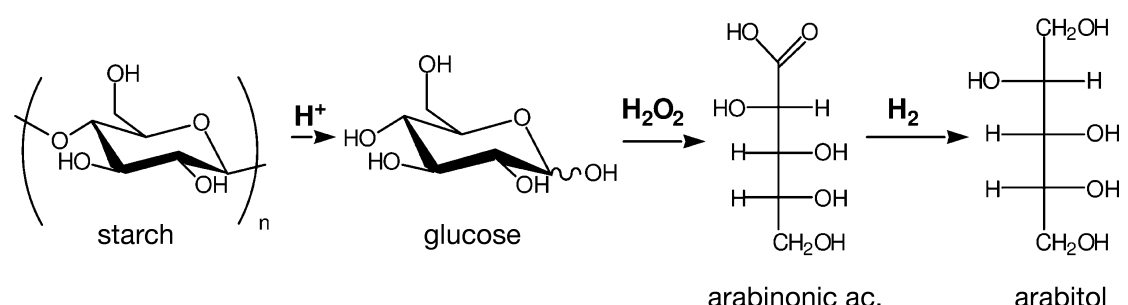

Scheme 3.2

Lactose Abbadi et al. [22] have studied the oxidation of lactose, a co-product of the milk industry, on $\mathrm{PtBi} / \mathrm{C}$ catalyst at $\mathrm{pH}$ 7. Lactobionate was formed transiently and subsequently converted into 2-keto-lactobionate with a final yield of 


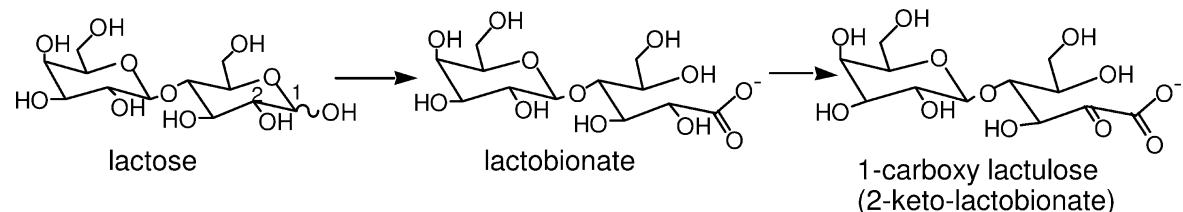

Scheme 3.3

ca. $80 \%$ (Scheme 3.3). Starting from lactobionate without pH control, 2-ketolactobionate was obtained with $95 \%$ selectivity, but the oxidation reaction stopped at $50 \%$ conversion due to the poisoning of $\mathrm{Pt}-\mathrm{Bi} / \mathrm{C}$ catalysts.

Carboxylic Acids Obtained by Fermentation of Carbohydrates Lactic (2-hydroxypropionic) acid obtained by fermentation of glucose and polysaccharides is used by NatureWorks (Cargill/Dow LLC) to prepare polylactide (PLA), a biodegradable or recyclable polymer with a potential production of $140000 \mathrm{t} \mathrm{a}^{-1}$ (Scheme 3.4) [23]. This and other potential useful reactions from lactic acid have been reviewed by Datta and Henry [24].<smiles>CC(O)C(=O)OCC(C)C(=O)OC(C)C(=O)OC(C)C(=O)OC(C)C(=O)OC(C)C(=O)O</smiles>

Scheme 3.4

3-Hydroxypropionic acid obtained by fermentation from glucose could also be a good candidate to produce various chemicals by catalytic routes [25].

Levulinic acid is obtained by hydrolysis of cellulose-containing biomass. R\&D is actively conducted at DuPont Co. to employ levulinic acid for the synthesis of pyrrolidones (solvents and surfactants), $\alpha$-methylene- $\gamma$-valerolactone [monomer for the preparation of polymers similar to poly(methyl methacrylate)], and levulinic acid esters (fuel additives) [26].

Furan Derivatives Catalytic processes used to obtain furan derivatives from carbohydrates and the catalytic routes from furan intermediates to chemicals and polymers have been reviewed by Moreau et al. [27]. Some of the main reactions are summarized in Fig. 3.2. From fructose or carbohydrates based on fructose (sucrose, inulin), the first transformation step is dehydration to 5-hydroxymethylfurfural (HMF). Fructose dehydration at $165{ }^{\circ} \mathrm{C}$ was performed in the presence of 


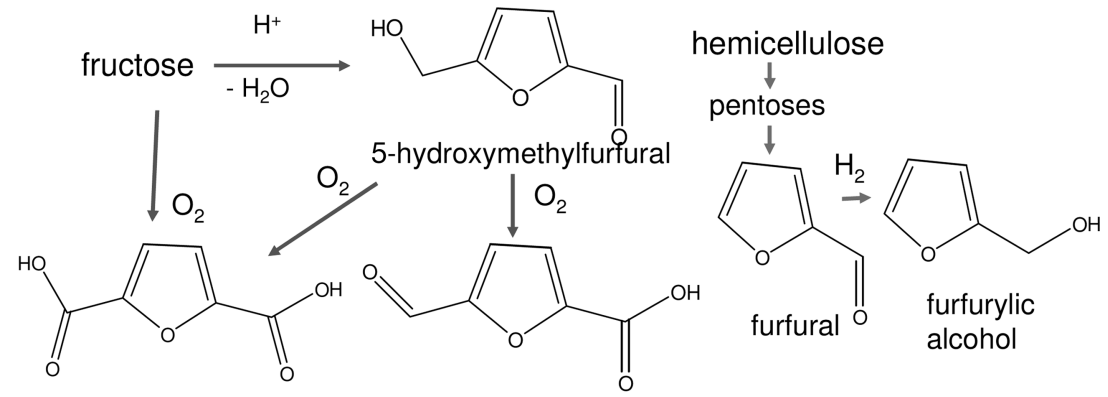

furan-2,5-dicarboxylic acid 5-formylfuran-2-carboxylic acid

Fig. 3.2 Catalytic reactions on furan derivatives.

dealuminated mordenite $(\mathrm{Si} / \mathrm{Al}=11)$ with a selectivity of $92 \%$ at $76 \%$ fructose conversion [28]. Starting from raw inulin hydrolysates for better process economy, the selectivity to HMF was up to $97 \%$ at $54 \%$ conversion [29].

The hydrogenation of HMF in the presence of metal catalysts (Raney nickel, supported platinum metals, copper chromite) leads to quantitative amounts of 2,5-bis(hydroxymethyl)furan used in the manufacture of polyurethanes, or 2,5bis(hydroxymethyl)tetrahydrofuran that can be used in the preparation of polyesters [30]. The oxidation of HMF is used to prepare 5-formylfuran-2-carboxylic acid, and furan-2,5-dicarboxylic acid (a potential substitute of terephthalic acid). Oxidation by air on platinum catalysts leads quantitatively to the diacid. [32]. The oxidation of HMF to dialdehyde was achieved at $90{ }^{\circ} \mathrm{C}$ with air as oxidizing in the presence of $\mathrm{V}_{2} \mathrm{O}_{5} / \mathrm{TiO}_{2}$ catalysts with a selectivity up to $95 \%$ at $90 \%$ conversion [33].

Furfural is obtained industrially $\left(200000 \mathrm{t} \mathrm{a}^{-1}\right)$ by dehydration of pentoses produced from hemicelluloses. Furfurylic alcohol is obtained by selective hydrogenation of the $\mathrm{C}=\mathrm{O}$ bond of furfural, avoiding the hydrogenation of the furan ring. Liquid phase hydrogenation at $80{ }^{\circ} \mathrm{C}$ in ethanol on Raney nickel modified by heteropolyacid salts resulted in a $98 \%$ yield of furfuryl alcohol [31].

Fatty Acid Esters and Fatty Alcohols Fatty acid esters are obtained by transesterification of triglycerides (vegetable oils) or by esterification of fatty acid with alcohol or polyols. Fatty alcohols are obtained by hydrogenation of esters on metal catalysts. Fatty acid esters and fatty alcohols are useful platform molecules to prepare surfactants, emulsifier, lubricants and polymers.

Surfactants Fatty acid esters of glycerol are efficient surfactants obtained either by transesterification of triglycerides with glycerol (glycerolysis) or by esterification of fatty acids with glycerol. The challenge in both cases is to obtain, selectively, glycerol monoesters that are non-ionic surfactants with a good hydrophilic/hydrophobic balance. Glycerolysis reactions have been conducted on basic oxides to replace liquid bases. Glycerolysis of rapeseed oil on $\mathrm{MgO}$ catalysts gave a $63 \%$ 
yield of monoglyceride [34]. Glycerol monoester has been prepared by esterification of fatty acid with glycerol, using acidic solids instead of sulfuric acid [35-42].

Fatty acid esters of sugars are also very important biodegradable and biocompatible surfactants that are prepared either by transesterification of methyl ester with sugar on basic catalysts or by esterification of fatty acids with sugar on acidic catalysts. Liquid acids and bases have been replaced by enzymatic catalysis with lipase, giving a higher yield of monoester [43, 44], but solid catalysts have not been used extensively so far.

Alkylglucosides are a class of valuable commercial surfactants, particularly for cosmetics applications because of their biocompatibility. They are obtained by acetalization of carbohydrates with fatty alcohols in the presence of acid catalysts. Zeolites and MCM-41 have been used as acidic catalysts to achieve the acetalization of glucose with alcohols of different chain lengths $[45,46]$. Shape selectivity effects decrease the amount of oligomers formed and the activity and selectivity can be controlled with the $\mathrm{Si} / \mathrm{Al}$ ratio.

Lubricants Fatty acid esters could be suitable lubricants, but their resistance to oxidation and tribological properties need to be improved. This can be achieved by epoxidation of the fatty acids followed by alcoholysis of the epoxide (Scheme $3.5)$.<smiles>CCCCCCCC/C=C/CCCCCCCC(=O)OC</smiles><smiles>CCCCCCCCC1OC1CCCCCCCC(=O)O[Na]</smiles><smiles>CCCCCCCCC(O)C(O)CCCCCCCC(=O)O</smiles>

Scheme 3.5

The epoxidation of fatty acid methyl esters (FAME) is traditionally conducted in strong acidic media, e.g., with peracetic acid in sulfuric acid solutions. These reactions can be conducted by an environmentally benign route, however, in the 
presence of acidic solids. Thus, a mixture of FAME from sunflower oil has been epoxided with tert-butyl hydroperoxide (TBHP) at $363 \mathrm{~K}$ in the presence of TiMCM-41 catalysts to yield $98 \%$ conversion with $85 \%$ selectivity for mono-epoxy compounds [47]. In the same way Rios et al. [48] have used different Ti-MCM41 materials, with pores diameters ranging from 1.9 to $4.1 \mathrm{~nm}$, and amorphous $\mathrm{Ti} / \mathrm{SiO}_{2}$.catalysts with different Ti-dispersion to perform methyl oleate epoxidation with TBHP at $70{ }^{\circ} \mathrm{C}$. Selectivities $>95 \%$ were obtained whatever the structure of the supporting material, provided titanium is well dispersed. Alcoholysis with different alcohols of epoxidized FAME has been studied on acidic resins of various structure and acid strength $[49,50]$. The addition of methanol on epoxidized methyl oleate at $60{ }^{\circ} \mathrm{C}$ in the presence of Nafion entrapped in silica (SAC13) or of Amberlyst15, a sulfonated styrene-divinylbenzene copolymer, resulted in complete conversion with selectivity higher than $98 \%$.

Polymers Catalytic reactions involving $\mathrm{C}=\mathrm{C}$ bonds are widely used for the conversion of unsaturated fatty compounds to prepare useful monomers for polymer synthesis. Catalytic $\mathrm{C}-\mathrm{C}$ coupling reactions of unsaturated fatty compounds have been reviewed by Biermann and Metzger [51]. Metathesis reactions involving unsaturated fatty compounds to prepare $\omega$-unsaturated fatty acid esters have been applied by Warwel et al. [52]. Ethenolysis of methyl oleate catalyzed by ruthenium carbenes developed by Grubb yields 1-decene and methyl 9-decenoate (Scheme 3.6), which can be very useful to prepare monomers for polyolefins, polyesters, polyethers and polyamide such as Nylon 11.

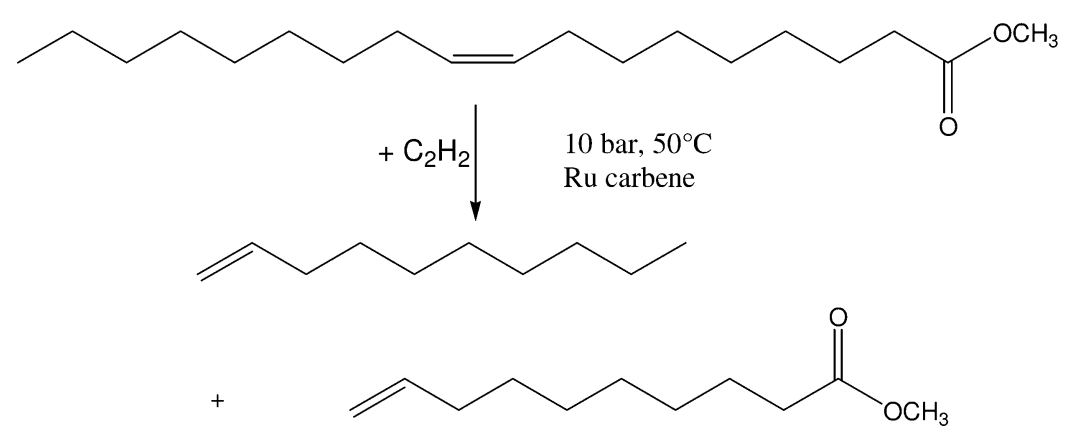

Scheme 3.6

Glycerol Glycerol is now mainly obtained as a co-product of triglyceride transesterification in the production of fatty acid esters employed as bio-diesel, Glycerol should find new outlets to optimize the economy of biodiesel production and to rebalance supply and demand [53]. As far as the production of chemicals is concerned, the main outlet of glycerol is the production of glycerol esters employed as emulsifiers, surfactants and lubricants. Fatty acid esters of glycerol are obtained either by transesterification of triglycerides with glycerol (glycerolysis) or 
by esterification of fatty acids with glycerol. The challenge in both cases is to obtain glycerol monoesters selectively.

The selective oxidation of glycerol leads to various valuable oxygenates (glyceric, tartronic, mesoxalic, and hydroxypyruvic acids, dihydroxyacetone). Besson and Gallezot [54] have shown that they can be obtained by oxidation with air of aqueous solutions of glycerol in the presence of carbon-supported platinum and palladium catalysts. The selectivity can be tuned by promotion of the noble metals with bismuth or by operating under controlled $\mathrm{pH}$. Thus, Garcia et al. [55] have found that the oxidation of glycerol at basic $\mathrm{pH}$ on palladium and platinum catalysts yielded $70 \%$ glycerate. Fordham et al. [56] have found that glyceric acid oxidation on $5 \%-\mathrm{Pt}-1.9 \%-\mathrm{Bi} / \mathrm{C}$ catalyst yielded $74 \%$ hydroxypyruvic at $80 \%$ conversion at acidic $\mathrm{pH}(3-4)$, but on the same catalyst under basic conditions (pH $10-11)$ a $83 \%$ yield of tartronate was obtained at $85 \%$ conversion. Abbadi and van Bekkum [57] have obtained 93\% selectivity for hydroxypyruvic acid at $95 \%$ conversion of glyceric acid on 5\%-Bi-5\%-Pt/C catalyst without $\mathrm{pH}$ regulation. More recently, the oxidation of glycerol was conducted in the presence of gold catalysts in basic medium $[58,59]$. The selectivity was shown to depend critically upon the size of gold particles [60].

Polyglycerols obtained by the dehydration of glycerol (Scheme 3.7) are employed as surfactants, lubricants, cosmetic, food additives, etc. Their esterification with fatty acids leads also to valuable emulsifiers or metal-working fluids. Zeolites have been used to take advantage of their shape selectivity effect to minimize oligomer formation, as described in two patents [61, 62]. A fair compromise between activity and selectivity has been obtained by Clacens et al. [63] using cesium-impregnated mesoporous MCM-41.

Acrolein has been obtained in $38 \%$ yield by glycerol dehydration at $360{ }^{\circ} \mathrm{C}, 25$ MPa in the presence of zinc sulfate [64].

Glycerol can be selectively dehydroxylated to either 1,2-propanediol (1,2-PDO), a chemical that can advantageously replace ethylene glycol as anti-freezing agent, or 1,3-propanediol (1,3-PDO), which when copolymerized with terephthalic acid

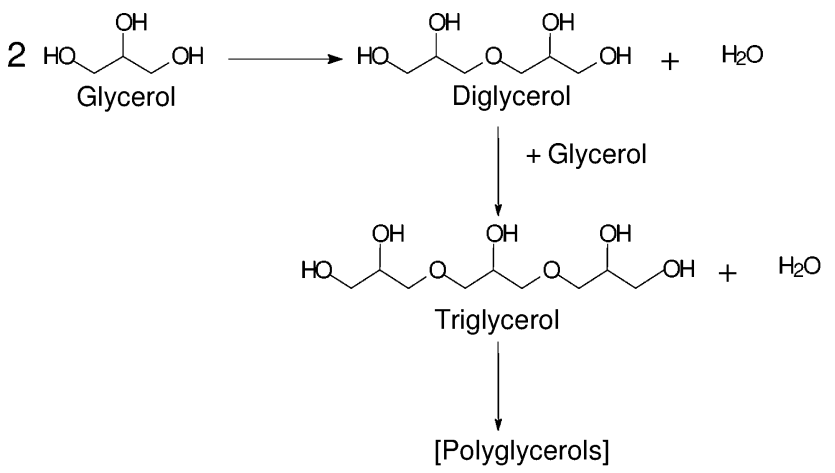

Scheme 3.7 
gives polyesters with unique mechanical properties. 1,3-PDO is currently produced by catalytic routes from ethylene oxide (Shell route) or acrolein (DegussaDuPont route). The microbial production of 1,3-PDO is under development by DuPont-Genencor to produce 1,3-PDO from glucose [65]. Chaminand et al. [66] have studied the hydrogenolysis of aqueous solutions of glycerol at $180{ }^{\circ} \mathrm{C}$ under 80 bar $\mathrm{H}_{2}$-pressure in the presence of supported metal catalysts in an attempt to produce selectively 1,2- and 1,3-PDO. The best selectivity (100\%) to 1,2-PDO was obtained by hydrogenolysis of water solution of glycerol in the presence of $\mathrm{CuO} /$ $\mathrm{ZnO}$ catalysts. To control the selectivity toward 1,3-PDO the reaction was conducted with rhodium catalysts with tungstic acid added to the reaction medium. The best selectivity to $1,3-\mathrm{PDO}(1,3-\mathrm{PDO} / 1,2-\mathrm{PDO}=2)$ was obtained by operating in sulfolane. Hydrogenolysis of glycerol has also been conducted on $\mathrm{Ru} / \mathrm{C}$ catalysts in the presence of Amberlyst resin, yielding mainly 1,2-PDO [67].

\subsection{3}

\section{From Biomass to Products via New Synthesis Routes}

The processing cost to convert biomass into valuable products can be greatly reduced under the following process conditions:

1. Decreasing the number of reaction steps via a one-pot reaction associating two or more catalytic steps. This can be achieved by multistep reactions carried out by cascade catalysis without intermediate product recovery, thus decreasing the operating time and reducing considerably the amount of waste produced.

2. Converting renewable feedstocks into a mixture of products that can be used as such in the synthesis or formulation of end-products. This approach is widely used in food and feed industries where there is no requirement to prepare specific molecules from bio-resources but rather mixtures of triglycerides, carbohydrates and proteins.

Approach (1) is very similar to classical synthesis routes except that the number of steps is reduced. In contrast approach (2) is quite different from chemical synthesis where the isolated products synthesized are used as such or in the formulation of end-products.

\subsubsection{One-pot Reaction with Cascade Catalysis}

There are several examples of one-pot reactions with bifunctional catalysts. Thus, using a bifunctional $\mathrm{Ru} / \mathrm{HY}$ catalyst, water solutions of corn starch (25 wt.\%) have been hydrolyzed on acidic sites of the Y-type zeolite, and glucose formed transiently was hydrogenated on ruthenium to a mixture of sorbitol (96\%), mannitol (1\%), and xylitol (2\%) [68]. Similarly a one-pot process for the hydrolysis and hydrogenation of inulin to sorbitol and mannitol has been achieved with $\mathrm{Ru} / \mathrm{C}$ catalysts where the carbon support was preoxidized to generate acidic sites [69]. Ribeiro and Schuchardt [70] have succeeded in converting fructose into furan2,5-dicarboxylic acid with $99 \%$ selectivity at $72 \%$ conversion in a one-pot reaction 
over a bifunctional acidic and redox catalyst consisting of cobalt acetylacetonate encapsulated in sol-gel silica.

$p$-Cymene (4), a precursor of $p$-cresol and various F\&Fs, can be obtained by dehydrogenation of $\alpha$-pinene at $300{ }^{\circ} \mathrm{C}$ in a continuous fixed-bed flow reactor in the presence of 0.5 -wt.\% $\mathrm{Pd} / \mathrm{SiO}_{2}$, as mentioned in the subsection on terpenes in Section 3.4.2.2 [14]. Interestingly, $p$-cymene has been produced under similar reaction conditions with nearly $100 \%$ yield from a mixture of di-pentene isomers (Sylvapine DP-378), showing that even unpurified raw materials can still be converted into the desired product in one step [71].

Cascade catalysis without recovery of intermediate products may require more than two steps, involving enzymatic, homogeneous, and heterogeneous catalysis. Several examples of this approach have been given [72, 73]; one of the most representative consists of a four-step conversion of glucoside into aminodeoxysugar without intermediate product recovery.

\subsubsection{One-pot Conversion into a Mixture of Products}

Conversion of Sugars into Polyols Deoxyhexitols consisting of $\mathrm{C}_{6}$ diols, triols, and tetrols are well suited to replace polyols derived from petrochemistry for applications in polyester and polyurethane manufacture. Investigations on controlled hydrogenolysis of carbohydrates have been performed mainly to produce $\mathrm{C}_{2}-\mathrm{C}_{3}$ polyols rather than higher molecular weight polyols $[74,75]$. In the framework of the European program STARPOL, starch hydrolysates were converted by combined hydrolysis-hydrogenation in a reactor loaded with $\mathrm{Ru} / \mathrm{HY}$ catalysts into sorbitol (Fig. 3.3). Then, in a second reactor, depending upon reaction conditions, sorbitol was converted either by dehydroxylation into $\mathrm{C}_{4}-\mathrm{C}_{6}$ products [76] or by

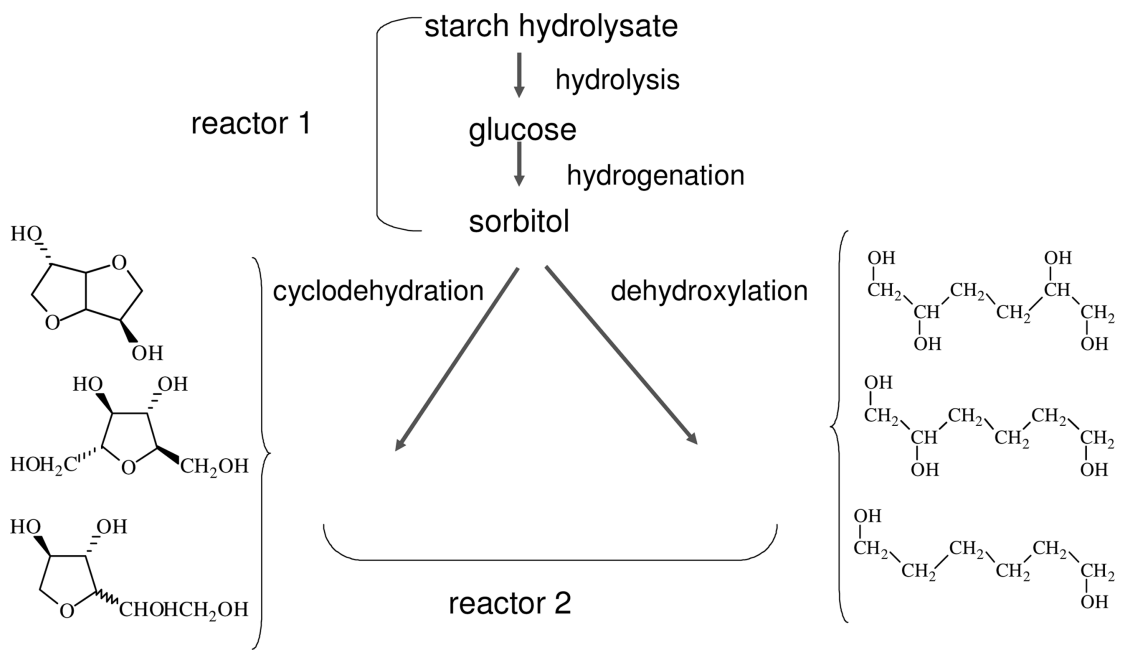

Fig. 3.3 Preparation of polyols (left-hand side: cyclic ethers; right-hand side: dehydroxyhexitols) from starch hydrolysates via a two-step process. 
cyclodehydration into cyclic polyols [77]. The dehydroxylation was performed under mild conditions to favor selectivity to deoxyhexitols. Copper-based catalysts, which have a low activity for hydrogenolysis of $\mathrm{C}-\mathrm{C}$ bonds, were employed to treat 20 wt.\% aqueous sorbitol solutions in the temperature range $180-240{ }^{\circ} \mathrm{C}$. Reactions carried out in the presence of $33 \% \mathrm{CuO}-65 \% \mathrm{ZnO}$ catalyst at $180{ }^{\circ} \mathrm{C}$ under $\mathrm{H}_{2}$-pressure yielded $73 \% \mathrm{C}_{4}{ }^{+}$polyols, and, more specifically, 63\% deoxyhexitols. Cyclodehydration of sorbitol and mannitol was carried out at $250{ }^{\circ} \mathrm{C}$ under 80 bar of $\mathrm{H}_{2}$, in the presence of $0.5 \% \mathrm{Pd} / \mathrm{C}$ catalyst and propionic acid that can be recovered by distillation at the end of reaction (Fig. 3.3). The reaction yielded cyclic ethers with the following selectivity at $90 \%$ conversion: $37.5 \%$ of isosorbide, $37.5 \%$ of 2,5-anhydromannitol, and $25 \%$ of 1,4-anhydrosorbitol (Fig. 3.3) [77]. The mixture of polyols, obtained either by dehydroxylation or cyclodehydration, was effectively employed to synthesize alkyd resins and make decorative paints with performances comparable to commercial ones.

Oxidation of Starch and Other Polysaccharides There is a challenge to convert polysaccharide polymers such as starch or cellulose into valuable end-products via one-pot process. This is difficult because these natural polymers are insoluble and partially crystallized and heterogeneous catalysts cannot be employed with these solid substrates. Hydrophilic starch obtained by partial oxidation is used in paper and textile industries and can be potentially applied in various applications, e.g., for the preparation of paints, cosmetics, and super-absorbents. Oxidation occurs at the $\mathrm{C}_{6}$ primary hydroxyl group or at the vicinal diols on $\mathrm{C}_{2}$ and $\mathrm{C}_{3}$, involving a cleavage of the $\mathrm{C}_{2}-\mathrm{C}_{3}$ bond to give carbonyl and carboxyl functions (Scheme 3.8). Several transition metal catalysts based on Fe, $\mathrm{Cu}$ or $\mathrm{W}$ salts have been proposed to activate $\mathrm{H}_{2} \mathrm{O}_{2}$ but the concentration of metal ions was quite high and they were retained by carboxyl functions in the modified starch [78].
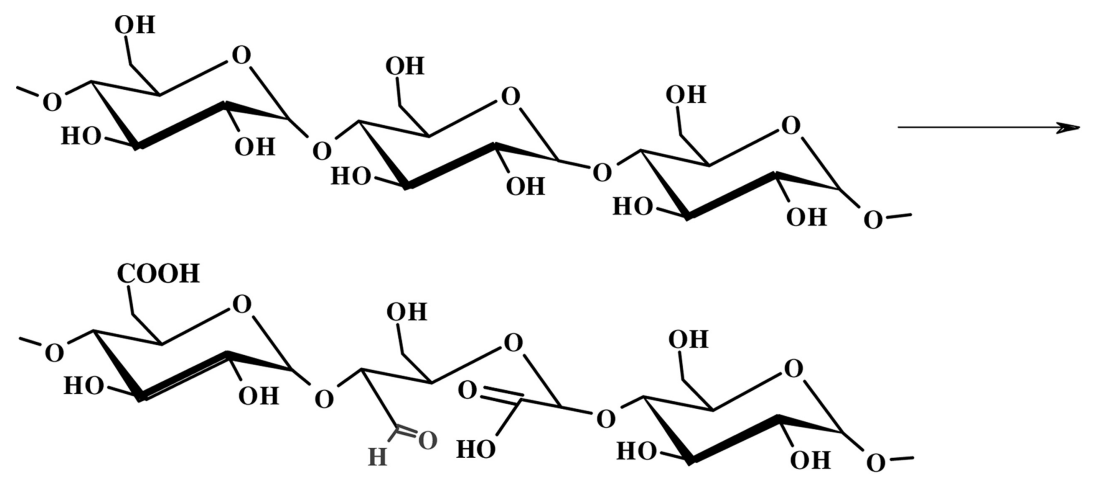

\section{Scheme 3.8}

Instead, native starch has been oxidized with $\mathrm{H}_{2} \mathrm{O}_{2}$ in the presence of soluble organometallic complexes to meet specific hydrophilic/hydrophobic properties needed for end-products to be used in paper, paint and cosmetic industries [79- 
Table 3.1 Oxidation of starch in aqueous suspension with $\mathrm{H}_{2} \mathrm{O}_{2}$ in the presence of iron phthalocyanine. ${ }^{\text {a) }}$ Effect of substrate/catalyst ratio.

\begin{tabular}{llr} 
Anhydro-glucose unit (AGU): Fe ratio & DS $_{\mathrm{COOH}^{\text {b) }}}$ & DS $_{\mathrm{C}=\mathrm{O}^{\text {b) }}}$ \\
\hline & & \\
$25800: 1$ & 0.70 & 3.20 \\
$12900: 1$ & 2.00 & 10.40 \\
$6450: 1$ & 2.00 & 9.00
\end{tabular}

a) Reaction conditions: $58^{\circ} \mathrm{C}$; $\mathrm{pH} 7$; reaction time: $7 \mathrm{~h}$; molar ratio $\mathrm{H}_{2} \mathrm{O}_{2}$ : $\mathrm{AGU}=1: 2.1$.

b) Degree of substitution expressed per 100 anhydroglucose units (AGU).

81]. The water-soluble iron tetrasulfophthalocyanine (FePcS) complex, which is cheap and available on an industrial scale, was also a very active and selective catalyst for the oxidation reaction. Starches of different origin (potatoes, rice, wheat, corn) were oxidized by $\mathrm{H}_{2} \mathrm{O}_{2}$ following two operating modes, viz. oxidation in aqueous suspension and oxidation by incipient wetness.

The oxidation of starch in aqueous suspension with $\mathrm{H}_{2} \mathrm{O}_{2}$ in the presence of iron phthalocyanine gives both carboxylic and carbonyl groups (Table 3.1). The best yields were obtained with a molar ratio $12900 / 1$ (0.0078 mol\%), but the oxidation was still quite efficient with 0.0039 mol\% of catalyst [ 25800 per anhydroglucose unit (AGU)/catalyst ratio]. The oxidized starch had almost the same final Fe-content as the initial potato starch. Still, the efficiency of this method in view of scaling up was limited by comparatively low activity and product isolation problems.

Native starch has been oxidized by the incipient wetness method by adding a small volume of water containing the dissolved catalysts to starch powder under continuous mixing, followed by addition of hydrogen peroxide to the impregnated solid under mixing. With a substrate/catalyst ratio of only $25800 / 1$ the oxidation yielded 1.5 carboxyl and 5.6 carbonyl functions per 100 AGU. The process was applied with success to the oxidation of starches of different physical and chemical properties (amylose/amylopectin ratio, granule size, temperature of gelatinization) obtained from different crops (potato, wheat, rice, corn). It has been further extended to cellulose, inulin and guar gum, giving a high degree of substitution (up to $\mathrm{DS}_{\mathrm{COOH}}=26.5$ and $\mathrm{DS}_{\mathrm{CHO}}=11.6$ for cellulose).

This catalytic system was very flexible because by simple modification of the reaction conditions it was possible to prepare oxidized polymers with the desired level of carboxyl and carbonyl functions. No waste was formed because the process did not involve any acids, bases or buffer solutions. The incipient wetness process is very easy to scale up. Hydrophilic starch was prepared in batches of $150 \mathrm{~L}$ and incorporated successfully in paint formulations. Good results were also obtained with in vitro and in vivo tests for cosmetic formulation. Interestingly, this is a rather unique example of a heterogeneous catalytic process involving a soluble catalyst and a solid substrate. 


\section{Modification of Starch and Other Saccharides by Grafting Hydrophobic Chains}

To prepare more hydrophobic starches for specific applications, the partial substitution of starch with acetate, hydroxypropyl, alkylsiliconate or fatty-acid ester groups has been described in the literature. A new route, however, consists of grafting octadienyl chains by butadiene telomerization (Scheme 3.9) [79, 82, 83]. The reaction was catalyzed by hydrosoluble palladium-catalytic systems prepared from palladium diacetate and trisodium tris $(m$-sulfonatophenyl)phosphine (TPPTS).
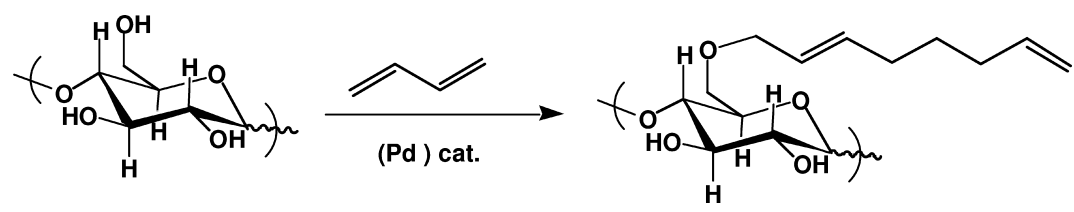

Scheme 3.9

The reaction was first conducted with success on sucrose [82]. The degree of substitution (DS) obtained was controlled by the reaction time. Thus, under standard conditions $\left(0.05 \% \mathrm{Pd}(\mathrm{OAc})_{2} / \mathrm{TPPTS}, \mathrm{NaOH}(1 \mathrm{~m}) / \mathrm{iPrOH}(5 / 1), 50{ }^{\circ} \mathrm{C}\right)$ the DS was 0.5 and 5 after 14 and $64 \mathrm{~h}$ reaction time, respectively. The octadienyl chains were hydrogenated quantitatively in the presence of 0.8 -wt.\% [RhCl(TPPTS $)_{3}$ ] catalyst in a $\mathrm{H}_{2} \mathrm{O}-\mathrm{EtOH}(50 / 10)$ mixture, yielding a very good biodegradable surfactant (surface tension of $25 \mathrm{mN} \mathrm{m}^{-1}$ at $0.005 \%$ concentration in water) [84]. Telomerization reaction was also conducted with success on other soluble carbohydrates such as fructose, maltose, sorbitol and $\beta$-cyclodextrin.

The transposition of this reaction to starch $[79,83]$ was challenging because this substrate is insoluble in water at room temperature and gelatinizes above ca. $70{ }^{\circ} \mathrm{C}$. The DS should be kept low enough because modified starch should not be too hydrophobic, and for obvious economic reasons the catalyst/starch ratio should be kept low. Figure 3.4 shows that the DS depends upon the amount

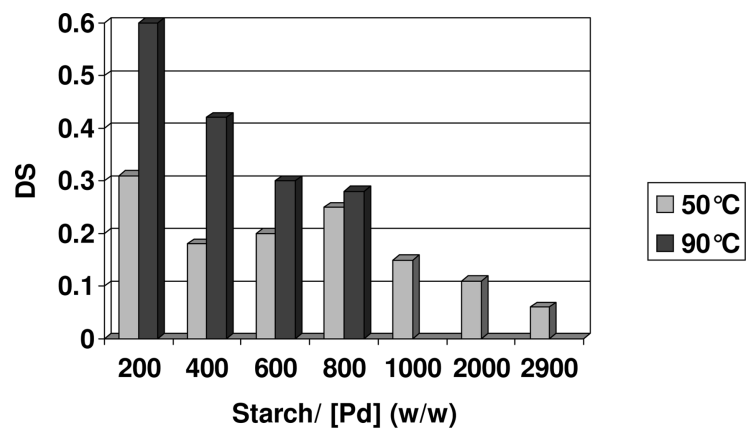

Fig. 3.4 Modification of starch by butadiene telomerization. Influence of the catalyst mass and temperature on the degree of substitution (DS). 
of catalyst and temperature. Modified starch with DS $=0.06$ obtained with $0.03 \%$ palladium at $50{ }^{\circ} \mathrm{C}$ meets the specification required for use as thickener for decorative paints. No palladium was detected in the modified polymer when the reaction was conducted in the presence of $0.05 \%$ palladium.

The etherified starch was further transformed by hydrogenation of the double bonds to yield the corresponding linear octyl groups using [ $\mathrm{RhCl}(\mathrm{TPPTS})_{3}$ ] catalyst soluble in EtOH $-\mathrm{H}_{2} \mathrm{O}$ mixtures. Complete hydrogenation was obtained at $40{ }^{\circ} \mathrm{C}$ under 30 bar of $\mathrm{H}_{2}$ after $12 \mathrm{~h}$ using 0.8-wt.\% Rh-catalyst [84]. Other catalytic transformations such as double bond oxidation and olefin metathesis could possibly be used to prepare other modified starches for various applications.

\section{5}

\section{Concluding Remarks}

So far, bioproducts are derived mainly from vegetables oils and carbohydrates. These raw materials issue from grains harvested primarily for food and feed and their productivity is low per area of cultivated land. In contrast, the non-grain portion of biomass, i.e., agricultural wastes (cobs, stalk, stovers) and vegetative biomass (trees, leaves, etc.) are hardly used despite their much larger availability. Vegetative biomass is based on lignocellulosic materials built on the intimate mixture of cellulose, hemicellulose and lignin that are difficult to process. Hemicelluloses are more easily hydrolyzed than celluloses and yield valuable pentoses such as xylose and arabinose that are potentially an important untapped renewable source of chemicals. Cellulose polymers are built on glucoside units connected via $\beta$-1,4-glycosidic linkages instead of $\alpha$-linkages in the case of starch; they are difficult to hydrolyze by chemical or enzymatic means, and the depolymerization of lignin is even worse. The development of an extended use of lignocellulosic materials for producing cost competitive bio-products must await progresses in depolymerization processes relying on improved biotechnologies. Nonetheless, chemicals such as vanillin can be obtained by catalytic oxidation of lignosulfonate [85]. In the meantime, pyrolysis of lignocellulosic materials yielding bio-oils can be used to extract chemicals.

Recent roadmaps on the use of renewable resources, such as "SusChem Implementation Action Plan 2006" [1], pledge the increasing use of biomass for the production of energy, chemicals and materials. Chemical companies worldwide have started extensive R\&D efforts to develop bio-based chemicals. Although the market price of renewable feedstocks is now comparable to that of fossil fuels, their processing cost is much higher. Synthesis routes from hydrocarbons have been improved for over a century whereas biomass processing is, comparatively, in its infancy. Alternative value chains have to be developed to decrease the cost and to increase the quality of end-products, because even if they may prefer biobased products, consumers do not want to pay more and have lower quality products. Life cycle analysis taking into account economic and societal issues due to 
the increased occupation of land have to be performed to validate biomass processing options and justify the use of biomass in the place of fossil feedstocks.

In view of the diversity and complexity of renewable feedstocks and of the potentially numerous bio-products at stake, integrated eco-efficient processes should be conducted in biorefineries. The biorefinery framework maximizes the value derived from biomass feedstocks by producing multiple products, valorizing byproducts and co-products, balancing energy production vs. energy consumption, and optimizing inputs and outputs, including waste treatment.

Within the biorefinery scheme we have identified three process options to produce chemicals by catalytic routes:

1. The degradation of biomass by gasification or pyrolysis leading to syngas and bio-oils, respectively. This approach provides primarily fuels rather than starting materials for bio-product synthesis. However, this is a possible route to bioproducts provided life cycle analysis demonstrates its validity in terms of economy and ecology. Partial catalytic degradation of biomass such as that obtained in aqueous phase reforming brings new opportunities.

2. The catalytic conversion of platform molecules produced by bioconversion of renewables into bioproducts. This is already the basis of many industrial processes, leading to important tonnages of chemicals and polymers from carbohydrates and triglycerides and fine chemicals from terpenes. This approach needs to be extended and process efficiency should be strengthened by designing more active and selective catalysts.

3. New synthesis routes based on one-pot reactions have to be developed to reduce processing costs drastically. Pure isolated products can be obtained by cascade catalysis involving two or more steps. A much larger gain in process economy should be obtained if a mixture of products suitable for a particular application, e.g., in paper, paint, polymer and cosmetic industries, can be prepared in a one-pot process starting from raw materials such as starch, cellulose and triglycerides. This is a current approach in food industry. Examples have been given in this chapter of the direct transformation of starch into a mixture of products that can be used as such to manufacture end-products.

To meet the challenge posed by the future increasing use of renewables, a large integrated research effort in chemistry, biochemistry, and genetics as well as in chemical and biochemical engineering will be required both in industrial and academic research centers. Biocatalysis is of primary importance, particularly in the early stage of processing to obtain platform molecules that will be converted into valuable chemicals by chemo-catalytic processes using either homogeneous or heterogeneous catalysts or a combination of both. Whatever the process options chosen, catalysis in all its forms will have a major role to play. At present, comparatively few researchers from industry and Academia are working in this area of catalysis. In view of the importance of environmental and economic challenges to meet, the workforce in Academia should be strengthened to develop formation and research. 


\section{References}

1 http://www.suschem.org/media. php? $\mathrm{mId}=4727$.

2 P.T. Anastas, J.C. Warner, Green Chemistry: Theory and Practice, Oxford University Press, New York, 1998, p. 30.

3 http://www.eere.energy.gov/biomass/

4 J.J. Bozell in Feedstocks for the Future, J.J. Bozell, M.K. Patel (Eds.), ACS Symposium Series 921, American Chemical Society, Washington, 2006, p. 1.

5 R.R. Davda, J.W. Shabaker, G.W. Huber, R.D. Cortright, J.A. Dumesic, Appl. Catal. B 2005, 56, 171.

6 G.W. Huber, R.D. Cortright, J.A. Dumesic, Angew. Chem. 2004, 43, 1549.

7 G.W. Huber, J.N. Chheda, C.J. Barrettt, J.A. Dumesic, Science 2005, 308, 1446.

8 A.V. Bridgwater, G.V.C. Peacoke, Renew. Sustain. Energy Rev. 2000, 4, 1.

9 D. Mohan, C.U. Pittman Jr., P.H. Steele, Energy \& Fuels 2006, 20, 848.

10 H. Pakdel, C. Roy, Bioresour. Technol. 1996, 58, 83 .

11 C. Amen-Chen, B. Riedl, C. Roy, Holzforschung 2002, 56, 281.

12 Th. Wilke, K.D. Vorlop, Appl. Microbiol. Biotechnol. 2004, 66, 131.

13 T. Werpy, G. Petersen, DOE/GO-1020041992, August 1, 2004.

14 D.M. Roberge, D. Buhl, J.P.M. Niederer, W.F. Hölderich, Appl. Catal. A: General 2001, 215, 111.

15 D. Buhl, D.M. Roberge, W.F. Hölderich, Appl. Catal. A: General 1999, 188, 287.

16 K. Hensen, C. Mahaim, W.F. Hölderich, Appl. Catal. A: General 1997, 149, 311.

17 H. van Bekkum, A.C. Besemer, Chem. Sustainable Develop. 2003, 11, 11.

18 F.W. Lichtenthaler, S. Peters, C.R. Chimie 2004, 7, 65-90.

19 N. Nicolaus, P. Gallezot, A. Perrard, J. Catal. 1998, 180, 51

20 M. Besson, F. Lahmer, P. Gallezot, P. Fuertes, G. Flèche, J. Catal. 1995, 152, 116.

21 L. Fabre, P. Gallezot, A. Perrard, J. Catal. 2002, 208, 247.

22 A. Abbadi, K.F. Gotlieb, J.B.M. Meirberg, H. Van Bekkum, Appl. Catal. A: General, 1997, 156, 105.

23 P.R. Gruber, Proc. $2^{\text {nd }}$ Int. Conf. on Green and Sustainable Chemistry, Washington DC, June 20-24, 2005, paper 149 .
24 R. Datta, M. Henry, J. Chem. Technol. Biotechnol. 2006, 81, 1119.

25 D.C. Cameron, NSF workshop, June 23-24, Washington 2005 http://www.cbe.iastate.edu/nsfbioren/ presentations/Cameron_Cargill.pdf.

26 L. Manzer in Feedstocks for the Future, J.J. Bozell, M.K. Patel (Eds.), ACS Symposium Series 921, American Chemical Society, Washington, 2006, p. 40.

27 C. Moreau, M. Belgacem, A. Gandini, Top. Catal. 2004, 27, 11.

28 C. Moreau, R. Durand, S. Razigade, J. Duhamet, P. Faugeras, P. Rivalier, P. Ros, G. Avignon, Appl. Catal. A: General 1996, 145, 211.

29 C. Moreau, R. Durand, C. Pourcheron, S. Razigade, Ind. Crops Prod. 1994, 3, 85.

30 V. Schiavo, G. Descotes, J. Mentech, Bull. Soc. Chim. Fr. 1991, 128, 704.

31 P. Vinke, H.E. van Dam, H. van Bekkum, Stud. Surf. Sci. Catal., G. Centi, F. Trifiro (Eds.), Elsevier, Amsterdam, 1990, Vol. 55, p. 147.

32 C. Moreau, R. Durand, C. Pourcheron, D. Tichit in Heterogeneous Catalysis and Fine Chemicals IV, H.U. Blaser, A. Baiker, R. Prins (Eds.) Stud. Surf. Sci. Catal., Vol. 108, Elsevier, Amsterdam, 1997, p. 399.

33 B.J. Liu, L.H. Lu, B.C. Wang, T.X. Cai, K. Iwatani, Appl. Catal. A: General 1998, $171,117$.

34 A. Corma, S. Iborra, S. Miquel, J. Primo, J. Catal. 1998, 173, 315.

35 H.E. Hoydonckx, D.E. De Vos, S.A. Chavan, P.A. Jacobs, Top. Catal. 2003, 27, 83.

36 M.S. Machado, J. Perez-Pariente, E. Sastre, D. Cardoso, A.M. de Guerenu, Appl. Catal. A: General 2000, 203, 321.

37 N. Sanchez, M. Martinez, J. Aracil, Ind. Eng. Chem. Res. 1997, 36, 1529.

38 S. Abro, Y. Pouilloux, J. Barrault, Heterogeneous Catalysis and Fine Chemicals IV, H.U. Blaser, A. Baiker, R. Prins (Eds.), Stud. Surf. Sci. Catal., Vol. 108, Elsevier, Amsterdam, 1997, p. 539.

39 Y. Pouilloux, S. Abro, C. Vanhove, J. Barrault, J. Mol. Catal. A: Chem. 1999, 149, 243.

40 W.D. Bossaert, D.E. De Vos, W. Van Rhijn, J. Bullen, P.J. Grobet, P.A. Jacobs, J. Catal. 1999, 182, 156. 
41 I. Diaz, C. Marquez-Alvarez, F. Mohino, J. Perez-Pariente, E. Sastre, J. Catal. 2000, 193, 295.

42 I. Diaz, F. Mohino, J. Perez-Pariente, E. Sastre, Appl. Catal. A: General 2003, 242, 161.

43 A.T.J.W. de Goede, M. van Oosterom, M.P.J. van Deurzen, R.A. Sheldon, H. van Bekkum, F. van Rantwijk, Biocatalysis 1994, 9, 145.

44 R.T. Otto, H. Scheib, U.T. Bornscheuer, J. Pleiss, C. Syldatk, R.D. Schmid, J. Mol. Catal. B: Enzym. 2000, 8, 201.

45 M.A. Camblor, A. Corma, S. Iborra, S. Miquel, J. Primo, S. Valencia, J. Catal. 1997, 172, 76.

46 M.J. Climent, A. Corma, S. Iborra, J. Miquel, S. Primo, F. Rey, J. Catal. 1999, 183, 76.

47 M. Guidotti, N. Ravasio, R. Psaro, E. Gianotti, L. Marchese, S. Coluccia, Green Chem. 2003, 5, 421.

48 L.A. Rios, P. Weckes, H. Schuster, W.F. Hölderich, J. Catal. 2005, 232, 19.

49 L.A. Rios, P.P. Weckes, H. Schuster, W.F. Hölderich, Appl. Catal. A: General 2005, 284, 155.

50 W.F. Hölderich, L.A. Rios, P.P. Werke, H. Schuster, J. Synthetic Lubric. 2004, 20, 289.

51 U. Biermann, J. Metzger, Top. Catal. 2004, 27, 119.

52 S. Warwel, P. Bavaj, M. Rüschgen Klaas, B. Wolff in Perspektiven Nachwachsender Rohstoffe in der Chemie VCH, Weinheim, 1996, p. 119.

53 S. Claude, Fett/Lipid 1999, 101, 101.

54 M. Besson, P. Gallezot, Catal. Today 2000, 57, 127.

55 R. Garcia, M. Besson, P. Gallezot, Appl. Catal. A: General 1995, 127, 165.

56 P. Fordham, M. Besson, P. Gallezot, Appl. Catal. A: General 1995, 133, L179.

57 A. Abbadi, H. van Bekkum, Appl. Catal. A: General 1996, 148, 113.

58 S. Carrettin, P. McMorn, P. Johnston, K. Griffin, G.J. Hutchings, Chem. Comm. 2002, 696.

59 S. Carrettin, P. McMorn, P. Johnston, K. Griffin, C. Kiely, G.A. Attard, G.J. Hutchings, Top. Catal. 2003, 27, 131.

60 S. Demirel-Gülen, M. Lucas, P. Claus, Catal. Today 2005, 102, 166.

61 US Pat 5349094, assigned to Henkel, 1992.
62 US Pat 5635588, assigned to Unichema, 1997.

63 J.M. Clacens, Y. Pouilloux, J. Barrault, Appl. Catal. A: General 2002, 227, 181.

64 L. Ott, M. Bicker, H. Vogel, Green Chem. 2006, 8, 214.

65 G.M. White, B. Bulthius, D.E. Trimbur, A.A. Gatenby, Patent WO 99 10356, 1999.

66 J. Chaminand, L. Djakovitch, P. Gallezot, P. Marion, C. Pinel, C. Rosier, Green Chem. 2004, 6(8), 359.

67 T. Miyazawa, Y. Kusunoki, K. Knimori, K. Tomishige, J. Catal. 2006, 240, 213.

68 P.A. Jacobs, H. Hinnekens, EP 0329923 for Synfina-Oleofina.

69 A.W. Heinen, J.A. Peter, H. van Bekkum, Carbohydr. Res. 2001, 330, 381.

70 M.L. Ribeiro, U. Schuchardt, Catal. Comm. 2003, 4, 83-86.

71 W.F. Hölderich, Catal. Today 2000, 62, 115.

72 A. Bruggink, R. Schoevaart, T. Kieboom, Org. Proc. Res. Dev., 2003, 622.

73 R. Schoevaart, T. Kieboom, Top. Catal. 2004, 27, 3.

74 C. Montassier, J.C. Ménézo, L.C. Hoang, C. Renaud, J. Barbier, J. Mol. Catal. 1991, 70, 99.

75 C. Montassier, J.M. Dumas, P. Granger, J. Barbier, Appl. Catal. A: General 1995, 121, 231.

76 B. Blanc, A. Bourrel, P. Gallezot, T. Haas, P. Taylor, Green Chem. 2000, 89.

77 T. Haas, O. Burkhardt, M. Morawietz, A. Vanheertum, A. Bourrel, DE 19749202, assigned to Degussa, 1999.

78 P. Parovuori, A. Hamunen, P. Forssell, K. Autio, K. Poutanen, Starch/Stärke 1995, 47, 19.

79 A. Sorokin, S. Kachkarova-Sorokina, C. Donzé, C. Pinel, P. Gallezot, Top. Catal. 2004, 27, 67.

80 A. Sorokin, S. Sorokina, P. Gallezot, Chem. Comm. 2004, 2844.

81 A. Sorokin, S. Kachkarova-Sorokina, P. Gallezot, WO Patent 2004/007560 A1, 2004.

82 V. Desvergnes-Breuil, C. Pinel, P. Gallezot, Green Chem. 2001, 3, 175.

83 C. Donzé, C. Pinel, P. Gallezot, P. Taylor, Adv. Synth. Catal. 2002, 344, 906.

84 C. Pinel, C. Donzé, P. Gallezot, Catal. Comm. 2003, 4, 465.

85 H.R. Bjorsvik, Org. Proc. Res. \& Dev. 1999, 3, 330. 
